Revista Iberoamericana, Vol. LXXIII, Núm. 218, enero-marzo 2007, 195-209

\title{
ÉTICA, ESTÉTICA Y EROTISMO: LA REFLEXIÓN CRÍTICA DE JORGE GAITÁN DURÁN
}

\author{
POR \\ PaOla Marín \\ Gustavus Adolphus College
}

El poeta colombiano Jorge Gaitán Durán (1925-1962) dedicó alrededor de siete años de su vida a Mito, revista fundada junto a Hernando Valencia Goelkel (1928-2004) y un hito indiscutible en la historia de la cultura colombiana. Es mi tesis en este ensayo que los comentarios de Gaitán Durán aparecidos en Mito presentan la más explícita cristalización de su propuesta de conciliar ética y estética, y de las dificultades inherentes a la búsqueda de una coherencia entre vida y escritura en un contexto sociocultural específico, objetivo que habría de marcar la totalidad de su labor literaria, su visión política y su itinerario vital. Si bien hay significativos estudios sobre la poesía de Gaitán Durán y del grupo de escritores de Mito, todavía hace falta un estudio detallado de su pensamiento en sus textos críticos. ${ }^{1}$ Pienso que es importante recordar la reflexión de autores como Gaitán Durán en este momento porque es en este tipo de intelectual comprometido donde se encuentran las bases para la historia de un pensamiento latinoamericano que asume de modo radical la problemática relación entre postura ética y estética, aspecto que años después los estudios culturales se encargarían de retomar y revaluar (véase Moraña, Nuevas perspectivas desde/sobre América Latina).

Gaitán Durán entendía la ética como la necesidad de anclar nuestra realidad humana en la responsabilidad hacia los demás, en su caso, a través de la labor intelectual. La complejidad del momento histórico nacional y mundial, según él, exigía del escritor "la respuesta a la situación, traducida en el descubrimiento de una condición humana de la cual no es posible huir" ("De las retóricas” 46). Anoto al margen que su uso de la palabra “situación” tiene relación directa con el humanismo sartreano, aspecto que discutiré más adelante.

En un período caracterizado por la violencia política y la izquierda emergente en Colombia, la posguerra europea, un marxismo que se va afianzando en las revoluciones china y posteriormente cubana, y el existencialismo francés con su fe en el compromiso del individuo en cada pequeño acto de su vida, para Gaitán Durán esa condición humana estaba signada por la barbarie pero también -aunque exigua- por la esperanza. Esa preocupación ética, íntimamente relacionada con su tiempo, será explorada en este

\footnotetext{
${ }^{1}$ En 1946 publicó su primer libro de poemas, Insistencia en la tristeza, prologado por Helcías Martán Góngora. Tenía entonces 22 años. En 1947 aparece Presencia del hombre; en 1951 Asombro, en 1953 su extenso poema titulado El libertino; en 1955, China; y en 1959, Amantes.
} 
artículo principalmente a través de su indagación de la naturaleza del lenguaje, del erotismo -tema también fundamental en su obra poética- y de su consideración del cine como arte moderno.

Para comprender la importancia de la labor intelectual de Gaitán Durán en relación con su necesidad ética de "llegar al universo del otro" en un mundo fragmentado expresión con la que en varios de sus artículos habría de definir la lucha del escritor contemporáneo- es necesario mencionar que, aunque fue sobre todo poeta, para él la lírica estaba condenada al fracaso en su compromiso con los tiempos. Mientras consideraba que el intelectual podía y debía reformar el mundo, destacaba que el verbo poético, particularmente en Latinoamérica, estaba signado por la soledad, pues la tarea del poeta, a diferencia del intelectual, no podía consistir en expresar una idea del hombre:

[El poeta] no sólo debe dar respuesta a su situación, sino que tiene que hacerlo con -y ahí reside la tensión- en términos de doble verdad: eficacia y belleza. (...) Es, en última instancia la misma historia del hombre; dividido entre la unidad abrumadora del signo y ese descubrimiento de su sér (sic) que es la violación del signo, hay días tremendos en que quiere decirlo todo (...) y el lenguaje -seco, enterizo, objeto ya, tradición- no le deja decir nada, lo vuelve poca cosa. ("De las retóricas” 448)

El lenguaje poético para él, por tanto, es un lenguaje petrificado, impotente frente a la riqueza y complejidad del presente, receptor del peso de una tradición caduca por estar basada en la noción de cultura como marco fijo (véase su crítica al modernismo hispanomericano en “De las retóricas”). Según Gaitán Durán, Latinoamérica se caracterizaba por ser un continente de historias en formación, no en el sentido de una cultura en estado de infancia frente a la europea, sino a manera de choque entre un lenguaje heredado de Europa y una realidad que lo desborda, aspecto que se evidencia con mayor claridad a mediados del siglo xx.

De esta manera, para el colombiano el poeta moderno que asume su “situación” (en sentido sartreano) y se despoja del sueño en la unidad del símbolo, está totalmente solo frente al lenguaje. Ya no puede apoyarse en la tradición a riesgo de caer en una falacia (véase mi artículo "Gaitán Durán y Barthes: realidad y poesía”). Frente a este estado de cosas, su respuesta fue asumir con similar intensidad tanto la solitaria pasión de la poesía, en la que veía la máxima expresión de la condición humana contemporánea por estar signada por el fracaso, como el compromiso con los demás a través de su labor como intelectual público.

Esta última vertiente habría de ejercerla principalmente por medio de la revista que fundó, y cuyos colaboradores asiduos fueron Hernando Téllez, Eduardo Cote Lamus, Pedro Gómez Valderrama, Fernando Charry Lara y Jorge Eliécer Ruiz, entre otros. Hay que resaltar que en esta publicación verían la luz textos claves de la cultura latinoamericana y mundial del momento como por ejemplo "Monólogo de Isabel viendo llover en Macondo”, texto descartado por García Márquez y rescatado por Jorge Gaitán Durán; un número entero dedicado a Borges, cuentos de Rulfo, poemas de Pizarnik, Guillén, Alexaindre y Cernuda, traducciones de Saint-John Perse, Benn y Pound, y comentarios a Camus, Bataille, de Beauvoir, Husserl y Nietzche, entre otros. La revista también se abrió a espacios previamente poco explorados en Colombia al publicar ensayos de crítica de 
cine, artes plásticas, sociología y socioliteratura. Con respecto a su enfoque político, cabe citar lo que el recientemente fallecido crítico Rafael Gutiérrez Girardot escribió con motivo de los 50 años de fundación de la revista:

Mito dio otras lecciones no menos valiosas: la convivencia intelectual y consecuentemente, la social. La revista no se adhirió a una determinada ideología ni a determinados intereses y vanidades políticas. Sus colaboradores eran de todos los colores, si así cabe decir: de izquierda, de conservatismo provinciano, de liberalismo moderado, apolíticos (...) En un país de enemigas facciones políticas esto era una lección de moral ciudadana y nacional. (“Los 50 años de Mito" 2)

Esta afirmación permite vislumbrar un aspecto esencial de la postura ética de Gaitán Durán, coincidente con su necesidad de compromiso con el presente de su patria: la importancia de no privilegiar un único punto de vista, pues para él lo que hacía falta eran espacios de diálogo. En una nota editorial aparecida en el número cuatro de Mito que denuncia la desaparición de los dos principales diarios colombianos debido a la censura oficial (El Tiempo y El Siglo), escribe: “No nos engañemos. La cultura y la libertad son indivisibles. Vano resulta reivindicarlas en el campo político y olvidarlas o negarlas en el social, el económico, el religioso o el literario. La libertad de expresión será total o no será de ninguna manera” (265). Por medio del proyecto de Mito y los numerosos artículos que allí publicarían, Gaitán Durán y Valencia Goelkel pretendían fomentar la cultura colombiana como un ámbito de libertad, de crítica y de reflexión. Ambos tenían la firme convicción de que la política no puede ser un discurso aislado de otros aspectos de la sociedad, pues sin debate no puede haber conciencia crítica y por consiguiente, no puede haber democracia. Con miras a este objetivo, Mito le da amplio espacio a la traducción de diversos textos de poesía, filosofía, literatura, arte, y crítica social y cultural. El mismo Gaitán Durán traducirá del francés al igual que Jorge Zalamea, y otros colaboradores lo harán del alemán y del inglés. Tal cosmopolitismo literario, lejos de ser alienante, correspondía a una postura ética porque permitía el diálogo, la difusión y la confrontación de ideas en un momento histórico que tanto en Colombia como en el resto del mundo se había distinguido por la barbarie y los dogmatismos.

En 1955 el país se encontraba saliendo (al menos en apariencia) del período conocido como la violencia por medio de la dictadura del General Rojas Pinilla (1953-1957). Sin embargo, la solución implantada tras la dictadura por los partidos políticos dominantes, más que abrir espacios democráticos tras un período de absolutismo, los restringió por medio del Frente Nacional (1957), un acuerdo bipartidista y excluyente de cualquier otra alternativa que no fuera el oficialismo liberal o conservador. El objetivo era evitar la prolongación del conflicto entre ambos partidos tras el asesinato del popular líder liberal Jorge Eliécer Gaitán y el consiguiente período dictatorial, pero las consecuencias de tal acuerdo implicaron el cierre de opciones para otras propuestas políticas. Este hecho ha sido identificado por diversos historiadores y politólogos como una de las causas del origen de la guerrilla colombiana que años más tarde (a mediados de los sesenta) iba a adquirir un cariz comunista. Frente a este trasfondo se comprende mejor por qué uno de los móviles principales del pensamiento de Gaitán Durán era la búsqueda de ámbitos para el diálogo y la confrontación ideológica, principalmente a partir del lenguaje. Había 
todavía en él cierta confianza en las posibilidades del arte y la literatura así como en el papel del intelectual que la caída de la cortina de hierro, el comienzo de los regímenes neoliberales a partir de los ochenta en Latinoamérica y la globalización de los medios con su explosión de imágenes, no había cuestionado aún de manera tan fuerte como hoy en día.

\section{LENGUAJE Y COMPROMISO POLÍTICO}

A pesar de las críticas que Gaitán Durán adelantó en Mito sobre el autoritarismo de Sartre y el consiguiente distanciamiento de éste con Albert Camus y otros intelectuales, este poeta veía la situación de Colombia de modo semejante a la visión sartreana de la crisis del lenguaje en la literatura perteneciente al período de entreguerras en Europa. Para Sartre, tal crisis respondía a que los aspectos desdeñados de la realidad histórica y psicológica pasaron bruscamente, después de silenciosa maduración, a un primer plano. Sin embargo, se contaba para designarlos con el mismo aparato verbal de antes: "La función del escritor es llamar al pan pan y al vino vino, si las palabras están enfermas, a nosotros nos toca curarlas” (Sartre 10). Ya varios críticos han indicado cómo Les Temps Modernes fue uno de los modelos de Mito, si bien señalan que no fue una imitación galicada de la revista fundada por el pensador francés (véanse Gutiérrez Girardot, Gómez Valderrama, Romero). Gaitán Durán tenía un sentido de la universalidad necesario para salir del provincianismo de las letras y la política colombianas, para revaluar una institución literaria cuya pompa y grandilocuencia habría de caracterizar también los discursos de los mandatarios, y que contribuiría a silenciar y condonar atrocidades tales como el asesinato por motivos políticos.

En la Colombia de 1955 “universalidad” no era, como es hoy para varios críticos, un sinónimo más de “canónico”, "hegemónico” o "excluyente” sino que reflejaba la necesidad de una apertura al mundo que permitiera así la autorreflexión, pues lo extranjero no era (o es) un concepto monolítico susceptible de obliterar lo nacional sino que debía alimentarlo. Como afirma Silviano Santiago, el problema para el intelectual latinoamericano no es la influencia cultural extranjera en sí misma. De hecho, este autor brasileño ve como el aporte esencial de escritores como Cortázar o Borges precisamente su destrucción sistemática de los conceptos de unidad y de pureza, al hacerles perder su peso de superioridad cultural: "a medida que el trabajo de contaminación de los latinoamericanos se afirma, se muestra más y más eficaz” (mi traducción, 18).

En una visión semejante, en su comentario sobre Historia universal de la infamia de Borges, Gaitán Durán destaca al escritor argentino como un intelectual que logra establecer un equilibrio entre "los movimientos culturales del mundo y los elementos de nuestra vida como hombres colocados en determinado medio, entre paisajes e historias en formación” (113). Esta nota sobre Borges, aparecida en el número 2 de la revista en el año 1955, enfatiza el valor de búsqueda de un pensamiento a constituirse a partir del diálogo que habría de tener la revista Mito. También explica, en parte, por qué la redacción de un Diario sería parte esencial del quehacer literario de Gaitán Durán, ya que para él era importante consignar su pensamiento como un hombre en medio de "paisajes e historias en formación” y como intelectual interesado en el gran texto del mundo (parafraseando al mismo Borges), y comprometido con su propia situación en sentido sartreano: “Lejos de 
ser relativistas afirmamos que el hombre es un absoluto. Pero lo es en su hora, en su medio, sobre su tierra. Lo que es absoluto lo que mil años de historia no pueden destruir es esta decisión [sic] irremplazable, incomparable, que toma en este momento en relación con estas circunstancias” (Sartre 10-11).

En este contexto no es gratuito el nombre escogido para la revista. "Mito”, de un modo que no es explícito, evoca las polémicas que se estaban gestando en los cincuentas alrededor de ese tema a través de pensadores como Lévi-Strauss, Mircea Elíade y Ernst Cassirer, al igual que la visión de Latinoamérica presente en la obra de escritores latinoamericanos como Fuentes, Cepeda Samudio o García Márquez, que revaluaban el mito no como una forma atrasada de conciencia sino como una conciencia distinta, fundamentalmente totalizante y ambigua. Nicolás Suescún comenta así una conversación con Valencia Goelkel sobre el nombre de la revista:

(pusieron en el editorial) una frase medio deshonesta y tortuosa diciendo que la revista se iba a ocupar de desmitificar una serie de valores y prejuicios y todo eso, pero fue por decir algo. Jorge se había enamorado del término y yo también. Pero Valencia Goelkel no pudo dejar de desconocer que la revista fue en realidad, como dijo Téllez, "el antimito nacional”, por incluir escalofriantes testimonios sobre la vida cotidiana y ocuparse de la política y del cine como un medio propio del siglo que merecía igual atención que la literatura. (1)

Coincidiendo con varios intelectuales de su tiempo -como por ejemplo Ángel Rama en la revista Marcha-una de las mayores preocupaciones de Gaitán Durán fue la búsqueda de una coherencia entre lo estético y lo político, entre poesía y realidad, a través de un lenguaje que en Colombia venía con una acendrada carga de autoritarismo ideológico y con el peso de una verbosidad que bien entrado el siglo veinte todavía justificaba un régimen de hacendados. Si se piensa en su visión de la labor del poeta anteriormente expuesta, está claro que esta preocupación coincide con su cuestionamiento de la unidad del símbolo en la poesía hispanoamericana y con su señalamiento de que el verbo poético debe asumir el compromiso con su momento, aunque tal empresa esté condenada al fracaso.

Es por eso que, conciente de las injusticias inherentes a un país semifeudal, en su extenso ensayo político titulado La revolución invisible, Gaitán Durán defendería la necesidad de una verdadera reforma agraria en Colombia. Tal aspecto irresuelto, con el paso del tiempo, sigue siendo el foco de un conflicto que ha devenido en el desplazamiento de grandes volúmenes de población y en el control de grandes extensiones de tierra por la tríada guerrilla, paramilitares y narcotráfico.

A través de Mito como publicación esencialmente literaria y frente a la gravedad de la situación de Colombia, Gaitán Durán y Valencia Goelkel buscaron crear un ámbito para plantear la tensión entre problemáticas estéticas y humanas. En su "Presentación a Mito", ambos autores proponen la complementariedad (no la univocidad) de política y arte: "Intentaremos presentar textos en donde el lenguaje haya sido llevado a su máxima densidad o bien a su máxima tensión. Más exactamente, en donde aparezca o una problemática estética o una problemática humana (...) Sospechamos la ineptitud de las soluciones hechas" (2). 
En este sentido encuentro cierta relación con una idea presente en El placer del texto, donde Barthes afirma que la literatura es una puesta en crisis del lenguaje. Es posible hacer un paralelo con Mito como propuesta que intenta acercarse al límite que el pensador francés ubicó entre el texto de placer, “el que contenta, colma y proviene de la cultura”, y el texto de goce "el que pone en estado de pérdida, desacomoda, hace vacilar los fundamentos históricos, culturales, psicológicos del lector, la congruencia de sus gustos, de sus valores y recuerdos" (25). Como manera de acercarse a esa ambigüedad que le importaba tanto a Gaitán Durán como expresión de lo humano, en Mito se establece un contrapunto entre literatura y filosofía que regirá la totalidad de las entregas, al igual que los comentarios sobre literatura extranjera que encubrían una crítica velada a la situación nacional. Así, en Mito, la ficción era un manera de aproximarse a la realidad.

El número 10 de Mito, dedicado simultáneamente a la fenomenología -vertiente filosófica basada en la intelección de las cosas mismas que busca progresiva y rigurosamente una verdad-y al surrealismo -arte de lo inmediato y del automatismo psíquico-es un buen ejemplo de la búsqueda de un espacio para la problemática interrelación de cuestiones tanto estéticas como éticas, pues la fenomenología y el surrealismo eran maneras de responder al progresivo desmoronamiento de la realidad occidental en un período de posguerra. Para los editores de Mito, que aparecería cada tres meses por un período de siete años que concluyó con la temprana muerte de Gaitán Durán, los dos eran maneras posibles de iluminar la realidad nacional y de alcanzar la lucidez. De allí que, cuando en la introducción a la revista Gaitán Durán escribe junto a Valencia Goelkel que "pretendemos dialogar y discutir con gentes de todas las opiniones y creencias, esa será nuestra libertad (3), cuando en La revolución invisible afirma que "la fuerza de una posición no proviene del desprecio, ni siquiera del talento o de una posición ideológica, sino de la independencia y la conciencia” (319), cuando publica en Mito la carta del intelectual comunista Darío Mesa, quien critica duramente a la revista, por citar algunos ejemplos, muestra que su intento no es procurar una solución, es decir, una ideología única. La postura ética de Mito, su deseo de incidir en la situación nacional desde la cultura, consistía así en crear un ámbito para confrontar modelos de pensamiento, para proveer herramientas de reflexión que permitieran el diálogo entre diversas posiciones. El valor de tal línea editorial puede ser mejor apreciado si se considera que el exterminio por diferencias de opinión y la carencia de una democracia efectiva ha caracterizado la mayor parte de la historia moderna de Colombia.

En consonancia con esta búsqueda de múltiples perspectivas, el Diario de Gaitán Durán no es un texto privado sino que fue publicado por entregas en Mito, mostrando en ocasiones un paralelismo cronológico y una coherencia de actitud entre los dos proyectos. De hecho, su Diario también conjuga reflexiones de todo tipo: políticas, artísticas, literarias, fragmentos poéticos. Siguiendo la acertada definición de Sarah de Mojica, es el diario de un poeta-ensayista (160), por lo tanto la unidad de forma la proporciona la poesía como actitud humana global, inherente a cada instante de la vida. En mi opinión, el Diario como género fronterizo y receptor de diversas formas de escritura le permite explorar a Gaitán Durán la ambigüedad del lenguaje, y sintetiza así su tentativa estética y humana de modo semejante a sus artículos publicados en Mito, ya que son textos que van con el tiempo cronológico, histórico, con la vida. Como afirma el autor en su reseña sobre la novela Los mandarines, de Simone de Beauvoir: 
De cierta manera nos encontramos más cerca del ensayo que de la novela, pero la novela nos permite acercarnos más a un mundo psicofisiológico dado. Las ideas expuestas por hombres y mujeres en plena actividad, que intentan vivir lo que piensan y en ello tienen éxito o fracasan, nos tocan y nos conmueven más que las ideas abstraídas de la realidad, movidas por un rigor didáctico. (“Comentario a Los mandarines”, 49)

“Intentar vivir lo que se piensa” es la característica esencial del poeta ensayista Gaitán Durán. Tambien podría decirse “intentar vivir lo que se escribe”, pues en ese mismo texto él establece cómo los personajes de la novela deben escoger entre comunicarse a través de su obra o a través de una acción política, "buscan una coherencia que es ideal e imposible" (47). Como ellos, el escritor quiso asumir la ambigüedad de lo humano. Ambigüedad que es, para decirlo con sus propias palabras en uno de sus comentarios sobre el cine de Federico Fellini, “cuando las vidas de los personajes se requieren mutua e indispensablemente para lograr la tensión poética, que encarna la gloria y la miseria de la condición humana” (“Nota sobre La Strada” 127). Para Gaitán Durán el ser sólo tiene sentido en comunidad.

Otra vertiente de esta preocupación claramente ética se encuentra en su más extenso ensayo político, titulado La revolución invisible, cuando afirma que la función del intelectual es la búsqueda de lo "universal concreto" y que debe insertar el aislado fenómeno económico o científico en la complejidad de la vida política social y cultural. Para él, “en una era de especialistas los intelectuales son especialistas en ideas generales, en relaciones entre los hombres y entre el hombre y el mundo" (321). El término "universal concreto" también encarna la problemática de la ambigüedad, pero esta vez como forma de que lo especializado participe de la totalidad y complejidad de la vida, de la realidad de un país, por medio del intelectual. En su Diario habría de expresar: "No debemos desocupar nuestra tierra con un ademán elegante o melancólico, sino convertir una tierra amorfa y pestilente en una patria” (287). Recuérdese cómo la postura ética de Mito consiste en contribuir a crear un ámbito de libertad, una patria para situarse frente a la historia y desde donde mirar. Esto tendrá una fuerte relación con el Diario, en el que Gaitán Durán desarrolla una mirada desde el “afuera” de la condición colombiana, ya que es esencialmente un diario de viaje.

Significativamente, en el primer número de Mito el poeta publicó un comentario acerca de la interpretación de la polémica Sartre-Merleau Ponty que hace Simone de Beauvoir en la novela Los mandarines, al que me referí anteriormente. Gaitán Durán resalta cómo los personajes "rechazan tomar partido entre dos mundos", son a la vez “extranjeros en la historia y comprometidos con la historia”. Este artículo ayuda a dilucidar la situación del escritor como intelectual frente a su patria y las razones que lo llevaron a Mito como posibilidad de comunicación: “La nota importante de Los mandarines es la de que no obstante sus fracasos históricos, Henri y Robert no pierden la esperanza ni cesan de hacerse preguntas sobre su propia condición y sobre la necesidad de comunicar con los otros" (“Comentario a Los mandarines” 49). Patria sería, según este texto, la posibilidad y la libertad de comunicar con otros, no los límites territoriales, lo cual ayuda a comprender la inclusión en la revista de ideas provenientes de distintas latitudes.

Aunque parezca contradictoria, la siguiente afirmación de su Diario es la otra cara del deseo de construir una patria, la decepción frente a la imposibilidad de la comunicación: 
"Súbitamente abandonamos todo porque sentimos que no lograremos resistir más, porque nos consideramos extranjeros en nuestra propia patria o desconocidos en nuestra familia" (287). Por un lado, Gaitán Durán viaja cuando la situación en Colombia le es insoportable -este fragmento del Diario es de 1959-; por otro, no pierde la esperanza como los personajes de Beauvoir y continúa la labor de forjarse un ambiente en el cual ser escuchado a través de Mito. La revista y el mismo Gaitán Durán habrían de ser objeto de múltiples críticas y, aún peor, de grandes incomprensiones. Se tildó a la revista de extranjerizante y de servir a los intereses de una burguesía decadente (por ejemplo las cartas de Darío Mesa y Jorge Child) y el poeta, como el mismo comenta en su Diario, fue acusado por los reaccionarios de ser comunista, y de ser reaccionario por parte de los comunistas. La situación colombiana no ha cambiado mucho. La polarización continúa definiendo el debate político e intelectual en Colombia en nuestra época, tras haber marcado el exterminio masivo de los miembros del Partido Unión Patriótica en los ochenta por parte de la ultraderecha, y se ha agudizado bajo el gobierno de Alvaro Uribe, de manera que cualquier grupo defensor de los derechos humanos es tildado por el gobierno de “cómplice” de la guerrilla, incluyendo en 2003 a las mismas Naciones Unidas. ${ }^{2}$

EROTISMO Y CRÍTICA A LA CULTURA

Un artículo clave para desentrañar el pensamiento de Gaitán Durán es "Sade contemporáneo”, aparecido en 1955 en el primer número de Mito, el cual fue posteriormente ampliado por el autor y titulado El libertino y la revolución (1960). Sade es actual a mediados del siglo xx porque la crisis de la civilización occidental tras la Segunda Guerra mundial hace evidente el fracaso de sus fundamentos, aspecto que el Marqués ya había explorado. El interés de Gaitán Durán en una figura como la de Sade radicó precisamente en su eregimiento de una ética individual y absoluta que reconocía como hipocresía los valores sociales considerados como cimiento de la conducta humana. Esta hipocresía Sade la sufriría en carne propia: "Realista bajo el rey, republicano bajo la república, el marqués es encarcelado por el rey y por la república” (“Sade contemporáneo” 7). Así, teniendo en cuenta que Colombia se encontraba bajo la dictadura de Rojas Pinilla en el momento de la publicación de este texto y considerando que fue el primer artículo de Gaitán Durán en Mito, es imposible no considerarlo una sátira encubierta a la situación del país.

El poeta quiere preguntarse sobre la propia condición y la de los otros. En este sentido Sade se constituye en un referente esencial para Gaitán Durán, pues el punto de partida de toda ética es precisamente la pregunta por lo que significa actuar como ser humano, por cómo empezar a demarcar el comportamiento humano. No es posible siquiera acercarse a la cuestión ética "sin referirnos a la noción de naturaleza humana, su humanidad o

\footnotetext{
${ }^{2}$ Basta citar la entrevista de junio de 2005 de la periodista María Isabel Rueda con el ex-magistrado de la Corte Suprema Carlos Gaviria sobre las elecciones presidenciales de 2006 para Semana, la principal revista de opinión de Colombia. En ella le pregunta si es comunista por haber propuesto una coalición con varias agrupaciones políticas, incluyendo algunas de izquierda. Gaviria replica: “¡No! Lo que pasa es que la promesa del Estado social de derecho se incumplió. Y defender la Constitución de 1991 ahora se ve como extrema izquierda”.
} 
inhumanidad” (Borradori 37), y esto es precisamente de lo que se ocupa Sade. Aunque es obvio que los sueños del noble francés no podrían ser aplicados a la sociedad en general, es posible estar de acuerdo con Bataille, cuyo pensamiento también sería de gran interés para Gaitán Durán:

(...) hay en nosotros, momentos de exceso: esos momentos ponen en juego el fundamento de nuestra vida; es inevitable para nosotros llegar al esfuerzo por el que tenemos la fuerza para poner en juego lo que nos fundamenta. Es, muy al contrario, negando tales momentos como desconoceríamos lo que somos. En su integridad, el pensamiento de Sade es la consecuencia de esos momentos que la razón ignora. (El erotismo 223)

Esto es fundamental para comprender la inclinación del poeta colombiano por el erotismo como reconocimiento del aspecto oculto de la condición humana, sin el que cualquier propuesta humanista quedaría trunca. En su excelente ensayo sobre la poesía de Gaitán Durán titulado “Eros y política”, Gutiérrez Girardot destaca que este poeta fue el primer escritor en lengua española en tratar el erotismo como tema de reflexión política. En un momento en el que la cuestión política y social para la mayoría de los intelectuales comprometidos se centraba exclusivamente en la liberación de los grupos indígenas o de los obreros, "Gaitán Durán comprendió que el problema político y social anterior es la liberación del individuo” (52). Si bien el poeta resaltó la importancia del compromiso político como por ejemplo en la teología de la liberación, igualmente consideraba al erotismo como un eje de reflexión ética fundamental. Para Gutiérrez Girardot, el eros en Gaitán Durán es político porque es lo que hace al individuo conciente de su realidad, de modo que lo que se llama “trascendencia, un más allá, es sólo una deformación ideológica del elemento racional del hombre” (53). En este sentido, es un aspecto ético fundamental, tanto a nivel individual como de la totalidad de la cultura.

Hay otro punto esencial que pone en contacto al colombiano con Sade, y que cabe suponer como otro de los motivos de su inclinación por éste: los dos comparten lo que Roland Barthes denomina "el goce en el hedonismo profundo de toda cultura y en la destrucción de esa cultura: gozar simultáneamente de la consistencia de su yo (es su placer) y de la búsqueda de su pérdida” (El placer del texto 48). Barthes, al igual que ve en Sade esa alternancia, sostiene que mientras el lenguaje de su narraciones es completamente convencional, lo que narra es totalmente subversivo. Gaitán Durán también nota esta característica del noble francés: "En la personalidad del Marqués la farsa y la verdad están agresivamente unidas, no pueden existir sino mistificándose mutuamente, se atraen y rechazan dentro de una constante inversión de papeles, en cuyo movimiento perpetuo la una toma a cada instante la apariencia de la otra” ("Sade contemporáneo” 6). Cabe recordar aquí la orientación de Mito y su búsqueda expresa de no privilegiar una sola postura ideológica. Cité antes cómo Gaitán Durán considera que "la libertad de expresión será total, o no será,” y en este comentario suyo acerca del Marqués trasluce la idea de que las verdades unívocas se acercan peligrosamente al absolutismo.

En su propio caso, el poeta manifiesta la subversión de la cultura a través de su propia reflexión literaria sobre el erotismo: "Sólo la poesía puede capturar el erotismo. Sólo ella embellece la siguiente paradoja: la inteligencia se afana por aferrarnos a lo que somos, por 
no dejarnos fluir hacia el olvido de nosotros mismos, el cual es precisamente recuerdo de lo más hondo del ser” (Diario 292). En esta cita se halla uno de los móviles de la poesía de Gaitán Durán, el poema como posibilidad de "mirada erótica”. Si embargo, paradójicamente el poema también es "estela que hiela un latido, de ahí en consecuencia, el fracaso de todo poema en apresar aquello que está vivo” (Cobo Borda 152). De allí la importancia de las demás formas de escritura que exploraría Gaitán Durán, especialmente los textos que publicaría en Mito, pues son testimonio de su creencia en el individuo como base de una transformación y de un humanismo con raíces directas en la experiencia psicofisiológica.

Tal búsqueda tiene fuerte relación con su interés en figuras no sólo como el Divino Marqués (llamado así por los surrealistas franceses), sino también por Genet (como Sade, también traducido por Gaitán Durán) y Artaud (que aparecería en el No. 8 de Mito y quien propuso una revolución del hombre que debía empezar por una rebelión del cuerpo y por lo tanto, de la escritura). Estas figuras consideradas enfermas por las instituciones sociales, son vistas en ese entonces como fuentes para una comprensión cabal del ser humano. Frente a la supuesta obscenidad que se le atribuía al arte, escritores como Henry Miller y Gaitán Durán declaran que la encuentran no en sus obras sino en la barbarie moderna, y consideran que la indagación de la sexualidad y la sensualidad hacen parte de una comprensión que permitiría un enfrentamiento del individuo con su condición humana real, y la construcción de una ética acorde con ella. Este aspecto anticipa algunas de las preocupaciones del feminismo y aunque carece de un aspecto clave que es la historicidad de los conceptos relacionados con el cuerpo, contribuye a revelar las implicaciones políticas inherentes a la importancia que Gaitán Durán le da al erotismo. Por ello, no es gratuita la publicación en Mito del texto de Miller titulado "La obscenidad y la ley de reflexión”, escrito originalmente en 1945:

Si insisto en la obscenidad de la guerra moderna, no es solamente porque yo esté en contra de la guerra, sino porque hay en las emociones ambiguas que ella inspira un elemento que me permite aprehender mejor la naturaleza de la obscenidad. Creo que nada sería tenido por obsceno si los hombres fuesen hasta el término de sus deseos más secretos. (Miller 81)

Es inevitable hacer un paralelo con la obscenidad de las guerras presentes. El recrudecimiento tanto de la guerra en Irak como de la guerra civil colombiana se ha justificado con argumentos simplistas que ocultan la naturaleza autoritaria de este hecho, como por ejemplo la supuesta defensa de la democracia frente a la amenaza de grupos terroristas que buscan impedir el progreso del mundo y/o del país.

Esta inmoralidad inherente a la negación del aspecto oscuro del ser humano es enunciada por Gaitán Durán en su Diario, a partir de una reflexión sobre el lenguaje: "Nuestro lenguaje actual se basa en una mentira; pone entre paréntesis los terribles abolengos de nuestra especie; (...) a su turno esta violencia desdeña imperialmente las pirámides de vocablos que el hombre construye para comunicar su progreso, para ser cada día más humano. Nuestro lenguaje no ha sido hecho para expresar la parte oscura del ser" (Diario 291). El poeta percibió las relaciones internas entre las estructuras de lo inhumano 
y los ejes de nuestra civilización. Es por eso que uno de los principales aportes de Mito fue su consideración del erotismo:

En un documento ilustrado con fotografías titulado "Historia de un matrimonio campesino" dio a conocer cómo un campesino puso candados en la vagina de su esposa para evitar la infidelidad. No sólo denunciaba los efectos de una castidad pervertida y perniciosa, extendida en Colombia, sino un rasgo medieval de la cotidianidad nacional. Era un rasgo, pues la feudalidad medieval era el sustento de los hacendados opresores. (Gutiérrez Girardot, “Los 50 años de Mito” 3)

Esta inclusión de erotismo y sexualidad apunta a un cuestionamiento de la cultura colombiana en particular y de la noción de cultura en el siglo xx en general, pues enlaza con la duda de Gaitán Durán acerca del lenguaje como fundamento de la civilización. Con las guerras mundiales aparece con gran evidencia el hecho de que el aparente progreso de Occidente estaba inexorablemente entretejido con el horror. Después de la muerte de Gaitán Durán, la Guerra Fría y las dictaduras latinoamericanas, supuestos bastiones del “progreso" económico, y más recientemente, las graves consecuencias del neoliberalismo en nuestros países y las guerras posteriores al 11 de septiembre, nos recuerdan la constancia de esta realidad.

Según George Steiner, un concentrado verbalismo definió la civilización occidental desde sus orígenes hebraicos y griegos, de modo que el discurso hablado recordado y escrito, se convirtió en la columna vertebral de la conciencia (véase El castillo de Barbazul). Sin embargo, tras la catástrofe de las guerras mundiales, apareció con nitidez la imposibilidad de pensar una nueva utopía que perpetuara el impulso hacia delante y por lo tanto, esa columna vertebral, el discurso, se resquebrajó. Las palabras, que habían mantenido las articulaciones del tiempo y las significaciones de valores fundamentales como el de progreso, se descubrieron como deterioradas por las falsas esperanzas y mentiras que habían proclamado. De allí la decadencia del discurso clásico, de ese carácter central de la palabra formado por un sistema jerárquico de valores y por el tropo de trascendencia que ellos expresan: “Una gramática explícita supone aceptar un orden; es una jerarquización (tanto más penetrante por haberse inculcado en edad temprana de la vida del individuo) de las fuerzas y valoraciones que prevalecen en el cuerpo político (las tonalidades de ‘clase’, ‘clasificación’ y ‘clásico’ están por supuesto emparentadas”) (Steiner 147).

Gaitán Durán percibió como Sartre esa retórica vacía que era el peligro del lenguaje, sobre todo el literario, en nuestro tiempo. En su Diario, así como en sus ensayos y en su poesía misma, no cesará de cuestionarse sobre el sentido del poema y de la literatura como forma. La cita de Steiner también permite comprender mejor por qué Gaitán Durán y Valencia Goelkel se niegan a privilegiar una ideología en Mito y a qué se referían cuando hablaban de "desmitificar” las palabras. Por eso allí mismo plantean cómo después de "limpiar" las palabras, sería el momento de "entrar a considerar problemas mayores como son sus conexiones con la moral y la libertad” ("Presentación a Mito”). En síntesis hay un interés, por parte del escritor colombiano por la exploración de la "problemática moral de nuestra época”, como afirma en su artículo sobre Sade. Esto abre el camino para 
comprender su preocupación esencial y la dificultad de resolverla: la tensión entre ética (lo abstracto, ideal e inhumano) y ser (lo humano y estético). El deseo de una consonancia entre moral y libertad.

El “REALISMO PoÉTICo” A TRAVÉS DEL CINE

Su comprensión de la crisis del lenguaje delineada anteriormente es lo que permite acercarse a la importancia que el cine tenía para Gaitán Durán, especialmente por su relación con el problema de la comunicación. En su artículo sobre La Strada de Federico Fellini, el poeta plantea cómo el cinematógrafo "se forma al mismo tiempo y con la misma fluidez que nuestra propia y cotidiana historia” (127). Por eso halla en él la expresión estética lograda de la fugacidad de la situación (recuérdese a Sartre) y la historia humanas: “(...) al realizar la unidad entre los avances del arte y de la industria, resume nuestro presente y nuestras posibilidades. Su imagen en movimiento permite descubrir otra dimensión del sér (sic), identifica la realidad y la apariencia, supera la distinción entre acto y potencia (127). Para Gaitán Durán era casi una obsesión la imposibilidad de reflexionar y actuar simultáneamente, es decir, de que el acto tenga sentido -o repercusión- en la vida de otros. Esta escisión entre ética y ser se vincula con la problemática principal, ya mencionada, del existencialismo de Sartre y Merleau-Ponty. Por eso en su ya citado Comentario a los mandarines habría de decir de los personajes que eran a la vez “extranjeros en la historia y comprometidos con la historia”, condición con la que se sentía identificado.

Sin embargo, para el poeta el cine supera tal cuestión al ser un arte de síntesis, que une instante y eternidad: "tiene la edad física del hombre moderno y se nutre de toda la historia” ("Notas sobre La Strada 128). Continuando con esta inquietud básica, también ve en dicho arte la consonancia entre “mecánica y expresión” que le permite alcanzar la posibilidad de abarcar el ser en toda su ambigüedad (incluida su situación existencial, que no significa un determinismo directo del momento histórico). En el cine, esa síntesis de momento -lo que él denomina su “dimensión vertiginosa” (“El que debe morir” 378)-y perdurabilidad por un lado, y técnica y expresión por el otro, iluminan la totalidad del razonamiento estético de Gaitán Durán. Esta preocupación por el estilo es lo que denomina “realismo poético”: “El estilo de La Strada es pasión pura (...) Eternamente confinado en el signo, ningún personaje literario alcanza semejante riqueza. Gelsomina es la realidad de la poesía” (129). Pasión pura implica una relación con la vida en su acepción más física -un arte que pueda zafarse de su "confinamiento en el signo" o en la palabra- punto que enlaza con su crítica al lenguaje (como se vio en el apartado sobre Sade) y con su preocupación por el erotismo. En consecuencia, no es extraño que se incline por expresiones humanas distintas a la literatura. Junto al ya citado sobre La Strada, se encuentran una larga serie de comentarios de su autoría sobre cine y artes plásticas aparecidos en Mito, lo cual coincide con su visión del intelectual como especialista en ideas generales. Teniendo en cuenta que él fue esencialmente un poeta, el que piense que la aptitud comunicativa del poema esté agotada en su tiempo ofrece una pauta para presumir que su obra poética es tan sólo un fragmento de su obra total y resaltar la importancia de su intensa labor en Mito como expresión de su necesidad imperiosa de unir arte y acción. 
Gaitán Durán quiso comprometerse y asumir otros significantes, para reconstruir una moral que desde la forma, expresara la condición humana. Es por eso que el cine lo deslumbra tanto. Un buen ejemplo es su artículo dedicado a la película El que debe morir, del director francés Jules Dassin, basada en la novela Cristo de nuevo crucificado, de Nikos Kazantzakis:

Sólo las novelas excepcionales -las de Balzac, Tolstoi o Proust- logran, con la misma fascinante densidad del cine, crear un mundo, es decir, la conjunción de un tiempo y un espacio propios, en donde se desarrollan relaciones irremplazables entre los hombres y entre el hombre y el objeto. Comprendo perfectamente al hombre de cine perseguido, condenado a hacer películas comerciales como Rififí, que encuentra en una novela griega, un sitio en el mundo. (378)

Esa perpetuación de una “conjunción de un mundo y de un espacio propios” es lo que le interesa radicalmente a Gaitán Durán del cine y la literatura. Su comentario muestra cómo ve en el arte la prolongación de esa conjunción como instante único, irreemplazable y lleno de valor por la expresión del carácter ambiguo y fundamental del ser humano, como "vibración pura e indispensable de la tragedia humana”, y como conciliación de las condiciones externas -la materia- con la experiencia interior del individuo. Lo principal es que el poeta advierte en esa realización estética, cómo el artista halla "un sitio en el mundo” al expresar la tensión perpetua de los personajes, "en búsqueda incesante del universo del otro”, mediante una interpretación acorde con la técnica cinematográfica que utiliza: “A la radiante Grecia de Kazantzakis, Dassin opone una Grecia abstracta y rigurosa, marco apenas para que la imagen cinematográfica traduzca lo esencial” (378). Es importante también que Gaitán Durán mencione que lo logra recreando una novela griega, pues el director es francés y Grecia un punto casi inexistente en el mapa de Occidente en el siglo xx. El colombiano apreciaría profundamente a otros artistas pertenecientes a los márgenes de Europa, como Kazantzakis y el poeta turco Nazim Hikmet, pues sus visiones de una conflictiva patria estaban muy cerca de la concepción que él mismo poseía de Colombia como territorio atroz y entrañable a la vez.

Gaitán Durán considera que ese modo de insertar la ficción en la condición humana real muestra el valor de la tentativa de Dassin como artista, pues buscar un lugar en la humanidad y comunicar con el otro son sinónimos para el poeta colombiano, y tiene similitudes con el papel que le asigna al intelectual en la sociedad como el que recupera las relaciones entre lo universal (lo abstracto) y lo concreto (la vida).

Para Gaitán Durán la escritura era una escogencia ética y por lo tanto, aunque trágico por la imposibilidad de conciliar poesía y realidad, un destino. No sólo fue poeta temprano y constante sino que no satisfecho con esa sola pasión creó Mito junto a Valencia Goelkel. Por su fuerte personalidad literaria y por el carácter múltiple de su obra, considero que es uno de los casos en los que el autor es lo más importante; por eso en el presente ensayo quise contribuir a mostrar cómo su obra fue esencialmente el conjunto de sus diversas preocupaciones concretadas literariamente.

Ya sea en sus escritos sobre cine, literatura, arte o política, su móvil fue siempre un lúcido apasionamiento por el presente que le tocó vivir, una conciencia de la crisis del 
lenguaje en el siglo xx en general y en el medio colombiano en particular, una preocupación por una patria como espacio en el cual poder dialogar y una desconfianza fundamental hacia los absolutismos de cualquier color. Por eso, quisiera concluir con este fragmento de su Diario: "La tradición no es un objeto definido eternamente (...) su abrumadora consistencia revela incontables grietas cuando la conciencia toma el riesgo de desmitificarla" (242). Es por esto que para él la solución no podía consistir en sustituir una ética por otra, un absoluto por otro, sino en asumir, como Sade, “la ejemplaridad de un fracaso". En esta época de fractura de los grandes relatos pero en la que sin embargo los dogmatismos siguen siendo nuestro pan de cada día, tanto en Colombia como a nivel mundial, Gaitán Durán nos recuerda, como habría de decir Roland Barthes en El placer del texto, que "la lucha social no puede reducirse a la lucha de dos ideologías rivales: lo que está en cuestión es la subversión de toda ideología” (124).

\section{BiBLiografía}

Barthes, Roland. El placer del texto y lección inaugural. México: Siglo XXI Editores, 1988.

Bataille, Georges. El erotismo. Barcelona: Tusquets Editores, 1992.

Borradori, Giovanna. La filosofía en una época de terror. Bogotá: Taurus, 2003.

Cobo Borda, Juan Gustavo. “Mito”. Poesía colombiana 1880-1990. Medellín: Universidad de Antioquia, 1980. 113-122.

De Mojica, Sarah. “El poeta como ensayista. Colombia. Revista Mito (1955-1962)”. Eco 260 (junio 1983): 160-174.

Gaitán Durán, Jorge. Obra literaria. Colección Biblioteca Básica vol. XVI. Edición de Pedro Gómez Valderrama. Bogotá: Colcultura, 1975.

“Comentario a Los mandarines”. Mito 1 (abril-mayo 1955): 49-54.

“De las retóricas”. Obra literaria. Colección Biblioteca Básica vol. XVI. Edición de Pedro Gómez Valderrama. Bogotá: Colcultura, 1975. 445-442.

“Diario”. Obra literaria. Colección Biblioteca Básica vol. XVI. Edición de Pedro Gómez Valderrama. Bogotá: Colcultura, 1975. 215-265.

“El libertino y la revolución”. Obra literaria. Colección Biblioteca Básica vol. XVI. Edición de Pedro Gómez Valderrama. Bogotá: Colcultura, 1975. 395-474.

“El que debe morir”. Mito 17 (diciembre-enero 1958): 378-381.

“La revolución invisible”. Obra literaria. Colección Biblioteca Básica vol. XVI.

Edición de Pedro Gómez Valderrama. Bogotá: Colcultura, 1975. 317-365.

“Nota sobre La Strada”. Mito 8 (junio-julio 1956): 127-130.

“Nota editorial”. Mito 4 (octubre-noviembre 1955): 265.

“Sade contemporáneo”. Mito 1 (abril-mayo 1955): 7-9.

"Sobre Historia universal de la infamia”. Mito 2 (junio-julio 1955): 113-114.

y Hernando Valencia Goelkel. "Presentación a Mito”. Mito 1 (abril-mayo 1955): 2-5.

Gómez Valderrama, Pedro. Jorge Gaitán Durán. Colección Clásicos Colombianos. Bogotá: Procultura, 1991. 
“El regreso para morir es grande”. Prólogo a Obra literaria de Jorge Gaitán Durán. Bogotá: Colcultura, 1975.

Gutiérrez Girardot, Rafael. “Eros y política”. Textos sobre Jorge Gaitán Durán. Ediciones Casa Silva. Bogotá: Fundación Casa de Poesía Silva, 51-58.

“Los 50 años de Mito”. Lecturas dominicales, El Tiempo (26 de abril de 2005).

Marín, Paola. "Realidad y poesía: Gaitán Durán y Barthes”. (Inédito)

Miller, Henry. “La obscenidad y la ley de reflexión”. Mito 8 (junio-julio 1956): 81-83.

Moraña, Mabel, editora. Nuevas perspectivas desde/sobre América Latina. Santiago de

Chile: Instituto Internacional de Literatura Iberoamericana y Cuarto Propio, 2002.

Romero, Armando. Las palabras están en situación. Bogotá: Procultura, 1985.

Rueda, María Isabel. “Al paredón con María Isabel”. Semana (15 de junio de 2005). http:/ /semana2.terra.com.co/opencms/opencms/Semana/sumario.html?id=1206

Santiago, Silvano. Uma Literatura nos Trôpicos. São Paulo: Perspectiva, 1978.

Sartre, Jean-Paul. "Presentación a Les Temps Modernes”. ¿Qué es la literatura? Buenos Aires: Losada, 1960. 153-162.

Steiner, Georges. El castillo de Barbazul. Barcelona: Gedisa, 1991.

Suescún, Nicolás. Periódico de la Universidad Nacional de Colombia 58 (30 de mayo de 2004). 
